\title{
Application of the Bloch-Schmigalla Method to Optimize the Organization of the Process of Repairing Unmanned Ground Vehicles
}

\author{
Jerzy Małachowski ${ }^{*}$, Jarosław Ziółkowski', Joanna Szkutnik-Rogoż', \\ Aleksandra Lęgas ${ }^{1}$, Mateusz Oszczypała ${ }^{1}$ \\ 1 Faculty of Mechanical Engineering, Military University of Technology, ul. gen. Sylwestra Kaliskiego 2, \\ 00-908 Warsaw 46, Poland \\ * Corresponding author's e-mail: jerzy.malachowski@wat.edu.pl
}

\begin{abstract}
The aim of this paper was to present the application of the Bloch-Schmigalla method in order to deploy work stations and create a military equipment repair model under field conditions. Proper allocation of repair stations is of crucial importance from the point of view of a given material's flow optimization. The aim of proper object allocation is such use of space that enables continuous, efficient and safe work. On the basis of numerical data, the advantages of using the Bloch-Schmigalla method for the optimal location of repair positions were presented. The proposal to optimize the organization of the repair process with using the Bloch-Schmigalla method entails multiple advantages e.g. decreasing the volume of transport activity size or time saving resulting from the rational arrangement of repair stations for unmanned ground vehicles.
\end{abstract}

Keywords: logistics, Bloch-Schmigalla method, equilateral triangles method

\section{INTRODUCTION}

The technological progress and dynamics regarding the changes occurring both in the operational environment as well as the possible methods and scenarios for conducting combat operations open up new and broad possibilities for the use of Unmanned Ground Vehicles (UGV) [5, $8,11,15,16,18,22,23,24,25]$, called robots. The special arguments in favor of UGV are the minimization of human losses, caused by the reduction of the risk of a direct threat to the health and life of a soldier through the use of robots in the modern battlefield. Additional arguments are: autonomy [17] and increasing the possibilities of sub-branches through the additional potential that UGV have. It concerns both the combat means [5, $22,23]$ as well as supplies $[18,24]$ and equipment for the contemporary robots often specialized for specific tasks $[25,26]$. The scope of the set of tasks carried out by UGV is a wide spectrum of their possibilities, ranging from patrolling the area, detecting explosives (mainly booby traps) and Improvised Explosive Devices (IED). In addition, the set of tasks also includes reconnaissance, detection of the position and movement of the opponent, as well as broadly understood logistical support. Such solutions are dedicated mainly to the pedestrian subunits performing tasks in difficult terrain $[11,15,16,19,22]$ or even for the special forces units. In the latter case, UGV may become particularly important given the very high unit cost of training a commando compared to a professional soldier. However, one should be aware of the fact that the robots adapted to perform tasks by formations of special forces units will be subject to a number of additional, often strict criteria. Therefore, at the current stage of UGV development, it is difficult to clearly determine in which direction the development of robots 
should proceed, i.e. whether towards highly specialized facilities and dedication to specific tasks, e.g. only reconnaissance, carrying explosives, logistical support or rather evolution should follow towards universal constructions with modular characteristics, enabling any robot configuration covering a wide spectrum of possibilities (intervention tasks, reconnaissance, transport or logistics support).

In an effort to reduce or completely eliminate casualties, unmanned ground vehicles (UGV) are increasingly often used instead of soldiers. Progressing robotization significantly influences the change in the ways of fighting [5, 8]. It is anticipated that in the future the battlefield will be dominated by ground vehicles and robots, as a consequence of which the man's participation in the armed conflict will be limited only to control over properly adapted robots and to monitor the course of activities [12, 16, 19]. Due to the autonomy of operation, the following classification of objects is adopted:

- remote-controlled by an operator equipped with sensors and navigation devices (human in the loop),

- semi-autonomous, requiring prior programming, supervision and acceptance of the target by the operator who finally decides about the mission (human on the loop),

- internally autonomous, ensuring the achievement of the goal without human intervention (human out of the loop),

- fully autonomous network-centric, the operation of which is based on receiving a command from the communications network and transferring it to a group of objects to perform a specific task (Network - Centric Autonomous Ground Vehicles) [5, 8].

Unmanned ground vehicles include the robotic sets designed, among others, to carry out the following tasks:

- transport, including the transport of ammunition, weapon systems, additional equipment intended to support operations, especially in harmful and dangerous conditions,

- detection, neutralization and removal of hazardous materials, e.g. IED,

- reconnaissance to provide the information about the detected dangerous objects and weapon systems of the enemy,
- control and inspection, e.g. monitoring and protection against threats,

- evacuation of soldiers from the places which are difficult to reach or exposed to direct enemy action,

- making passages in engineering dams and other natural and artificial terrain obstacles,

- providing automated steering center for other unmanned land platforms $[5,8,11,16$, $18,22,23]$.

\section{REPAIR OF MILITARY EQUIPMENT UNDER FIELD CONDITIONS}

The repairs of the military equipment (ME) are carried out in order to restore the technical fitness or technical service life resources. The scope of repairs depends on the scale of work and time necessary to carry them out. Repair detachments and mobile technical security elements perform military equipment repairs under field conditions within the scope and time determined by the superior or resulting from the character of their operations. The military equipment can be qualified for repair or included as irrecoverable loss depending on the extent of destruction or the size and nature of the damage. The basic criterion for qualifying $\mathrm{ME}$ in combat operations is the expected labor output of removing the detected damage. Repairs of the land technique can be divided according to a five-point scale, depending on the performance capabilities of the execution detachments and repair units $[4,6]$.

The following methods of repairing military equipment are distinguished under field conditions:

a) socket - a repair detachment performs a comprehensive repair of equipment at the place of mass damage or at the damaged equipment collection point,

b) service - a unit responsible for carrying out the repairs moves to the equipment damage location, where comprehensive repair is carried out,

c) element replacement - damaged assemblies, subassemblies and parts are replaced with technically efficient ones,

d) individual - consisting proper mounting of a repaired element to the same $\mathrm{ME}$,

e) mixed - a combination of the presented methods [7]. 


\section{REQUIREMENTS FOR UGV AND EXAMPLES OF USED ROBOTS}

In accordance with the assumptions of the $R o-$ botics and Autonomous Systems (RAS) publication, the main task of which is to determine the requirements of the US Army in the development of unmanned ground vehicles, more and more attention is focused on the autonomy of operations and cooperation with unmanned and manned weapon systems. Ground vehicles should be characterized by high mobility and the ability to perform tasks in difficult to reach terrain with varied surface. The most frequently determined minimum values of the parameters ensuring mobility depending on the size and weight of unmanned ground vehicles include $[5,8]$ :

- gradeability with a $60 \%$ gradient,

- traveling on a slope with a $40 \%$ gradient,

- overcoming vertical obstacles with the height of $600 \mathrm{~mm}$,

- crossing trenches with the width of $1000 \mathrm{~mm}$,

- minimum speed of about $30 \mathrm{~km} / \mathrm{h}$.

A specially designed suspension system, the use of efficient drive systems and appropriate weight distribution should ensure high UGV maneuverability and the ability to make turns in place or even the possibility of climbing stairs $[12,16,19]$. The use of hybrid propulsion systems can contribute to obtaining high torque and simultaneously reducing the noise level. Currently, the research on the legitimacy of using lighter and more efficient lithium-sulfur instead of lithium-ion batteries is being conducted. A properly selected power source provides the right energy balance for the electronic and optoelectronic systems of unmanned ground vehicles. Another very important structural element which should be characterized by failure-free operation is the environment recognition system, which includes, e.g. laser scanners, vision cameras, GPS systems, radars and location sensors. The most important challenge for ground robots will be self-reliant identification of the opponent and the ability to make decisions without the operator's interference. Table 1 presents the examples of unmanned ground vehicles depending on their weight, maximum range and the specificity of tasks performed.

When planning the organization of military equipment repairs based on the socket method, many methods are available to ensure the most favorable allocation of areas and workstations in the field. These methods include the BlochSchmigalla method, which is used for the optimal allocation of repair stations.

Table 1. Examples of used unmanned ground vehicles [Based on Depczynski 2017]

\begin{tabular}{|c|c|c|c|c|}
\hline No. & ULP & $\begin{array}{l}\text { Weight } \\
{[\mathrm{kg}]}\end{array}$ & $\begin{array}{l}\text { Maximum range } \\
{[\mathrm{m}]}\end{array}$ & Specification \\
\hline 1 & TMZ set & 35 & 600 & $\begin{array}{l}\text { - reconnaissance } \\
\text { - deactivation of dangerous objects }\end{array}$ \\
\hline 2 & Scarab & 50 & 350 & $\begin{array}{l}\text { - reconnaissance } \\
\text { - patrolling }\end{array}$ \\
\hline 3 & TM-5 set & 50 & 600 & $\begin{array}{l}\text { - reconnaissance } \\
\text { - deactivation and destruction of hazardous materials } \\
\text { - transport }\end{array}$ \\
\hline 4 & MRK-27 BT & 170 & 500 & - fire support \\
\hline 5 & Waran & 190 & 1000 & $\begin{array}{l}\text { - engineering recognition } \\
\text { - deactivation of dangerous objects }\end{array}$ \\
\hline 6 & Platform M & 800 & 1500 & $\begin{array}{l}\text { - reconnaissance } \\
\text { - fighting live force and equipment } \\
\text { - fire support } \\
\text { - patrolling } \\
\text { - sapper } \\
\text { - supply transport }\end{array}$ \\
\hline 7 & MRK-61 & 800 & 600 & $\begin{array}{l}\text { - liquidation of the consequences of technical failures of devices } \\
\text { with radioactive, biological and chemical materials }\end{array}$ \\
\hline 8 & Szatun & 1000 & 5000 & $\begin{array}{l}\text { - fire support } \\
\text { - reconnaissance } \\
\text { - transport as part of the support of airborne-amphibious units }\end{array}$ \\
\hline 9 & Wolk 2 & 1100 & 5000 & $\begin{array}{l}\text { - fire support } \\
\text { - reconnaissance } \\
\text { - patrolling } \\
\text { - strengthening the system of protection and defense of strategic } \\
\text { ballistic missile launchers }\end{array}$ \\
\hline 10 & $\begin{array}{l}\text { BAS-01GBM } \\
\text { Soratnik set }\end{array}$ & 7000 & 10000 & $\begin{array}{l}\text { - reconnaissance } \\
\text { - patrolling } \\
\text { - sapper } \\
\text { - supply transport } \\
\text { - evacuation of wounded }\end{array}$ \\
\hline
\end{tabular}




\section{BLOCH-SCHMIGALLA METHOD}

The Schmigalla triangles method is an approximate, stepwise method with unlimited choice of location on the nodes of a regular triangle grid. It is designed for spatial location of repair stations in such a way, so that the points between which there is the highest flow of a given material are so close to each other as possible $[1,3,9,14]$. These points are placed on the triangle grid, which makes it possible to develop an optimal allocation of even a large number of such points. Distributing the points on a grid of equilateral triangles is the basis for the further planning of spatial allocation of objects. The application of the BlochSchmigalla method allows better organization of transport, flow of material, information or people, through shortening the distances between points characterized by the highest movement intensity $[2,13]$. This method was elaborated by W. Bloch from Switzerland, and further developed and modified in 1968 by H. Schmigalla. The essence of this method is the distribution of the objects in a triangle grid disregarding the size, assuming the same distance between the objects $[2,20]$.

The primary aim of object allocation in the logistics system is to improve the flow of material goods. In order to create an analytic model, the following assumptions should be made:

a) technological connections between the objects being located are known and established in advance,

b) there is freedom in choosing the object allocation,

c) there are no connections between the objects with fixed location and the objects being localized.

The object allocation model adopted the following designations:

$m$ - number of allocated objects $(i=1,2, \ldots, m)$,

$c_{i j}$ - technological connections of the objects, quantities characterizing the flow rate of cargo between $i$-th and $j$-th object $(i=1,2, \ldots, m)$,

$d_{p q}$-links between locations, distance between $p$-th and $q$-th object location $(p, q=1,2, \ldots, m)$,

$x_{i p}, x_{j q}-$ deterministic variables, location of object $i$-th and $j$-th, at point $p$-th and $q$-th respectively.
Solving the object allocation problem in a logistics system comes down to finding the values of variables:

$$
\left\{x_{i p}\right\} ; i, p=1,2, \ldots, m
$$

which would satisfy the following criterion function:

$$
\sum_{i=1}^{m} \sum_{j=1}^{m} \sum_{p=1}^{m} \sum_{q=1}^{m} c_{i j} d_{p q} x_{i p} x_{j p}=\min
$$

with the following restrictions:

$$
\begin{aligned}
& \sum_{i=1}^{m} x_{i p}=1 ; p=1,2, \ldots, m \\
& \sum_{p=1}^{m} x_{i p}=1 ; i=1,2, \ldots, m
\end{aligned}
$$

$x_{i p}=\left\{\begin{array}{l}1, \text { if object } i \text { is in the place of object } p \\ 0, \text { otherwise }\end{array}\right.$

The presented $c_{i j}$ coefficients may concern the mass of transported materials, the number of transport batches, as well as transport operations $m$ of the objects related to the flow of materials and information [10, 14, 18, 21].

It is assumed that the optimal object allocation on the equilateral triangle grid takes place when the objective function "W" reaches the minimum value. The objective function expresses the product of the flow rate of any factor (e.g. damaged equipment) and its displacement distance.

The objective function can be expressed with the formula:

$$
W=\sum_{i=1}^{N-1} \sum_{j=1}^{N} S_{i j} L_{i j} \rightarrow \min
$$

where: $S_{i j}$ - connections between object $i$ and object $j$,

$L_{i j}$ - distance (measured in adopted modular units) between object $i$ and object $j$ [4].

The calculation process in the Bloch-Schmigalla method is carried out in two steps:

1. determining the order in which positions will be placed,

2. selection of locations for individual positions [14]. 


\section{ALGORITHM FOR THE PROCEEDINGS}

Determining the number of $N$ objects and technological connections between them is the most important step. Next, through converting the link matrix, the sequence of allocating in the triangle grid is determined, starting from the element $S_{i j}$ with the highest value, which indicates a pair of objects inter-linked the most. This pair of objects is placed in the central location of the equilateral triangle grid. In the event of many such pairs, the one with the most links to all objects has priority. The next step is to determine a successive object with the highest number of with objects selected to be allocated or those which had already been allocated. The next object after the first pair, if it is linked with two objects, is placed in the node, thus creating an equilateral triangle. If it has a connection with only one object, then it is placed in an adjacent node. The basis for locating the next object in the grid is the minimum sum of connections between the objects which had been already allocated. The arrangement of the objects should be presented graphically. After arranging all the objects on the triangle grid, a distance matrix is prepared and the value of the objective function is determined [20]. In the Schmigalla triangles method, the result of calculations is the allocation of positions to the locations and the shape of the surface on which each position should be spaced. The task is to determine the method of placing repair stations at which the amount of transport work understood as the sum of the product of the weight of transported materials and the distance will be minimal.

The following designations of individual repair stations for unmanned ground vehicles were adopted:

1. damage assessment area,

2. area for repairing engineering reconnaissance equipment,

3. night vision equipment repair area,

4. powertrain repair area,

5. control system repair area,

6. fire support equipment repair area,

7. video camera repair area,

8. chassis repair area,

9. chemical recognition sensor repair area.

The matrix of technological connections occurring between the work stations for unmanned ground vehicles is presented in Table 2. Table 3 indicates a pair of objects with the highest value of technological connections. The maximum value is 75 , corresponding to a pair of elements 1 and 4 , which means that the most common cause of unmanned ground vehicle failure were powertrain failures. Next, the sum of link intensity between the allocated and non-allocated objects was calculated and the results are illustrated in Table 4. The next object with the highest value of technological connections with objects already allocated is object 8 . Following the presented scheme, the sum of the intensity of connections between the considered repair stations was calculated and the results are illustrated in Table 5 .

The subsequent object with the most connections is object 3 , for which the most advantageous location on the grid of equilateral triangles should be determined. Figure 1 illustrates nine suggestions for the locations of the night vision equipment repair station. Next, the transport activity size should be calculated for all nine potential locations of the third object, which is illustrated in Table 6. Table 6 may suggest that the third object should be located in the place marked V (compared location shown in Figure 1). The above situation is illustrated in Figure 2.

After placing the next object with the highest sum of technological connections to the already

Table 2. Technological connections between the repair stations

\begin{tabular}{|c|c|c|c|c|c|c|c|c|c|}
\hline \multirow{2}{*}{ Station } & \multicolumn{9}{|c|}{ Technological connections between stations } \\
\cline { 2 - 12 } & 1 & 2 & 3 & 4 & 5 & 6 & 7 & 8 & 9 \\
\hline 1 & & 19 & 13 & 75 & 20 & 18 & 24 & 60 & 11 \\
\hline 2 & 19 & & 10 & 16 & 70 & 21 & 18 & 52 & 27 \\
\hline 3 & 13 & 10 & & 70 & 20 & 29 & 11 & 36 & 60 \\
\hline 4 & 75 & 16 & 70 & & 10 & 8 & 8 & 60 & 70 \\
\hline 5 & 20 & 70 & 20 & 10 & & 28 & 9 & 60 & 10 \\
\hline 6 & 18 & 21 & 29 & 8 & 28 & & 32 & 24 & 11 \\
\hline 7 & 24 & 18 & 11 & 8 & 9 & 32 & & 8 & 10 \\
\hline 8 & 60 & 52 & 36 & 60 & 60 & 24 & 8 & & 18 \\
\hline 9 & 11 & 27 & 60 & 70 & 10 & 11 & 10 & 18 & \\
\hline
\end{tabular}


Table 3. Indication of the link with the highest value

\begin{tabular}{|c|c|c|c|c|c|c|c|c|c|}
\hline \multirow{2}{*}{ Station } & \multicolumn{9}{|c|}{ Technological connections between stations } \\
\cline { 2 - 13 } & 1 & 2 & 3 & 4 & 5 & 6 & 7 & 8 & 9 \\
\hline 1 & & 19 & 13 & 75 & 20 & 18 & 24 & 60 & 11 \\
\hline 2 & 19 & & 10 & 16 & 70 & 21 & 18 & 52 & 27 \\
\hline 3 & 13 & 10 & & 70 & 20 & 29 & 11 & 36 & 60 \\
\hline 4 & 75 & 16 & 70 & & 10 & 8 & 8 & 60 & 70 \\
\hline 5 & 20 & 70 & 20 & 10 & & 28 & 9 & 60 & 10 \\
\hline 6 & 18 & 21 & 29 & 8 & 28 & & 32 & 24 & 11 \\
\hline 7 & 24 & 18 & 11 & 8 & 9 & 32 & & 8 & 10 \\
\hline 8 & 60 & 52 & 36 & 60 & 60 & 24 & 8 & & 18 \\
\hline 9 & 11 & 27 & 60 & 70 & 10 & 11 & 10 & 18 & \\
\hline
\end{tabular}

Table 4. Determination of the value of connections between the allocated stations and the remaining ones and indication of the next position with the highest value

\begin{tabular}{|c|c|c|c|c|c|c|c|c|c|}
\hline \multirow{2}{*}{ Station } & \multicolumn{9}{|c|}{ Technological connections between stations } \\
\hline & 1 & 2 & 3 & 4 & 5 & 6 & 7 & 8 & 9 \\
\hline 1 & & 19 & 13 & 75 & 20 & 18 & 24 & 60 & 11 \\
\hline 2 & 19 & 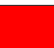 & 10 & 16 & 70 & 21 & 18 & 52 & 27 \\
\hline 3 & 13 & 10 & & 70 & 20 & 29 & 11 & 36 & 60 \\
\hline 4 & 75 & 16 & 70 & & 10 & 8 & 8 & 60 & 70 \\
\hline 5 & 20 & 70 & 20 & 10 & 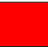 & 28 & 9 & 60 & 10 \\
\hline 6 & 18 & 21 & 29 & 8 & 28 & & 32 & 24 & 11 \\
\hline 7 & 24 & 18 & 11 & 8 & 9 & 32 & & 8 & 10 \\
\hline 8 & 60 & 52 & 36 & 60 & 60 & 24 & 8 & & 18 \\
\hline 9 & 11 & 27 & 60 & 70 & 10 & 11 & 10 & 18 & \\
\hline \multicolumn{10}{|l|}{ Sequence } \\
\hline 1 & & 19 & 13 & & 20 & 18 & 24 & 60 & 11 \\
\hline 4 & & 16 & 70 & & 10 & 8 & 8 & 60 & 70 \\
\hline$\Sigma$ & & 35 & 83 & & 30 & 26 & 32 & 120 & 81 \\
\hline
\end{tabular}

located objects, it is necessary to recalculate the sum of the intensity between the non-allocated and allocated objects (compared data presented in Table 7). The procedure should be repeated until all repair stations have been placed on the triangle grid. Table 7 shows that the chemical recognition sensors repair station should be located in the place marked IV (compared location shown in Figure 2). The above-mentioned situation is presented in Figure 3.

Table 8 shows that the second object should be located in the place marked VIII (compared location shown in figure 3). Figure 4 shows the allocation of six workstations. Table 9 calculates the transport activity size for the eight repair stations located to determine the latest location of the station marked with number 7. After applying this procedure, the optimal organization of all repair stations for unmanned ground vehicles was illustrated in Figure 5.
As a result, the Bloch-Schmigalla method has led to the determination of the optimal location of repair stations for unmanned ground vehicles in such a way that ensures the development of space so that the work could be realized continuously, efficiently and the points which are characterized with the highest value of technological connection were located as close to each other as possible.

\section{CONCLUSIONS}

Originally, the main purpose of using robots was to reduce the risk of casualties among own troops and to ensure the realization of tasks regardless of the combat environment. Currently, the main intended use of unmanned ground vehicles manufactured in many armies is to increase the military combat capabilities. Progressive robotization of the battlefield can contribute to 
Table 5. Determination of the value of technological connections between repair stations

\begin{tabular}{|c|c|c|c|c|c|c|c|c|c|}
\hline \multirow{2}{*}{ Station } & \multicolumn{9}{|c|}{ Technological connections between stations } \\
\hline & 1 & 2 & 3 & 4 & 5 & 6 & 7 & 8 & 9 \\
\hline 1 & & 19 & 13 & 75 & 20 & 18 & 24 & 60 & 11 \\
\hline 2 & 19 & & 10 & 16 & 70 & 21 & 18 & 52 & 27 \\
\hline 3 & 13 & 10 & . & 70 & 20 & 29 & 11 & 36 & 60 \\
\hline 4 & 75 & 16 & 70 & & 10 & 8 & 8 & 60 & 70 \\
\hline 5 & 20 & 70 & 20 & 10 & & 28 & 9 & 60 & 10 \\
\hline 6 & 18 & 21 & 29 & 8 & 28 & . & 32 & 24 & 11 \\
\hline 7 & 24 & 18 & 11 & 8 & 9 & 32 & . & 8 & 10 \\
\hline 8 & 60 & 52 & 36 & 60 & 60 & 24 & 8 & & 18 \\
\hline 9 & 11 & 27 & 60 & 70 & 10 & 11 & 10 & 18 & \\
\hline \multicolumn{10}{|l|}{ Sequence } \\
\hline 1 & & 19 & 13 & & 20 & 18 & 24 & 60 & 11 \\
\hline 4 & & 16 & 70 & & 10 & 8 & 8 & 60 & 70 \\
\hline$\Sigma$ & & 35 & 83 & & 30 & 26 & 32 & 120 & 81 \\
\hline 8 & & 52 & 36 & & 60 & 24 & 8 & & 18 \\
\hline$\Sigma$ & & 87 & 119 & & 90 & 50 & 40 & & 99 \\
\hline 3 & & 10 & & & 20 & 29 & 11 & & 60 \\
\hline$\Sigma$ & & 97 & & & 110 & 79 & 51 & & 159 \\
\hline 9 & & 27 & & & 10 & 11 & 10 & & \\
\hline$\Sigma$ & & 124 & & & 120 & 90 & 61 & & \\
\hline 2 & & & & & 70 & 21 & 18 & & \\
\hline$\Sigma$ & & & & & 190 & 111 & 79 & & \\
\hline 5 & & & & & & 28 & 9 & & \\
\hline$\Sigma$ & & & & & & 139 & 88 & & \\
\hline 6 & & & & & & & 32 & & \\
\hline$\Sigma$ & & & & & & & 120 & & \\
\hline 7 & & & & & & & & & \\
\hline
\end{tabular}

reducing the risk of casualties by using UGV in reconnaissance, sapper or patrol operations. The Russian experience related to participation in the conflict in December 2015 in the Syrian province of Latakia, confirm the possibility of using remotely controlled combat robots to carry out the missions previously reserved only for a man. The problem associated with robotization of the battlefield may be the determination of the allowed level of autonomy of the terrestrial robot, which

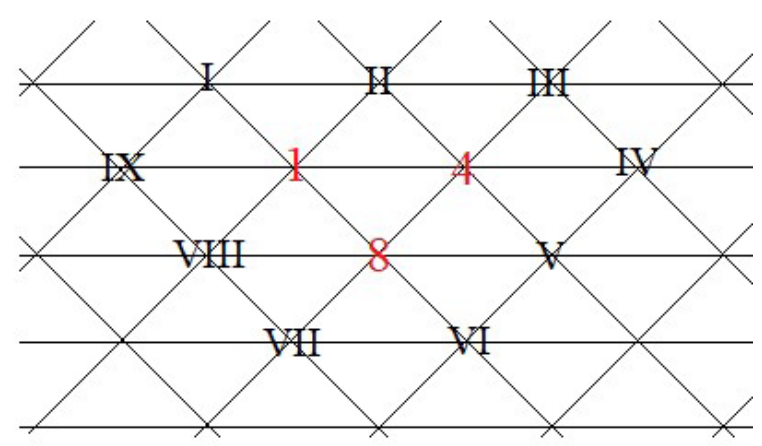

Fig. 1. Indication of possible nodes for the placement of the third object could independently make decisions to start or stop operations, simultaneously correctly interpreting the principles of international humanitarian law of armed conflicts.

The paper presents the application of the Bloch-Schmigalla method for optimizing the organization of the process of repairing unmanned ground vehicles. The essence of the BlochSchmigalla method is the allocation of repair stations in the triangle grid omitting their actual size, on the understanding that the distances between repair stations should be equal. The only real limitation of the described method in practice may be the varied size of allocated unmanned

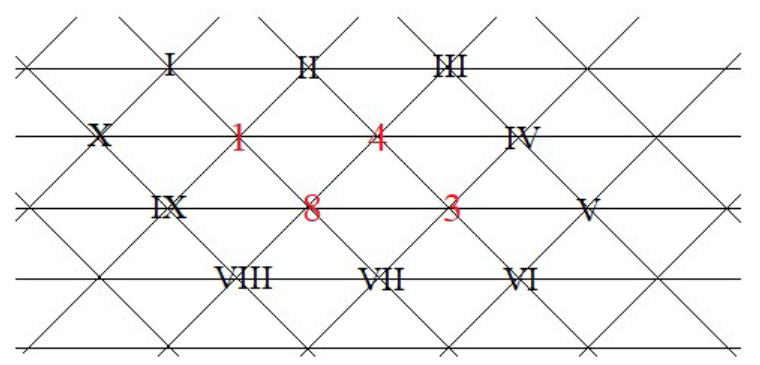

Fig. 2. Location of the next object 


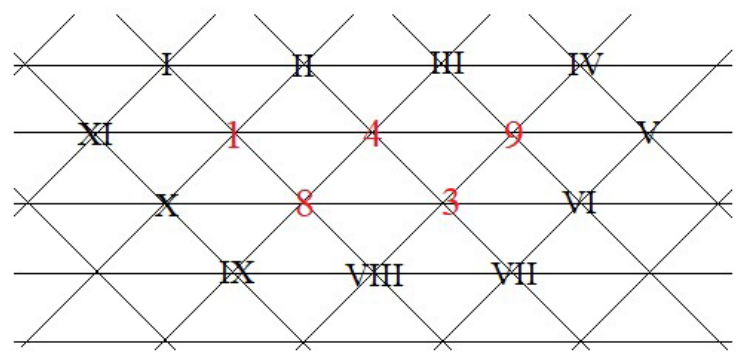

Fig. 3. Location of the ninth object

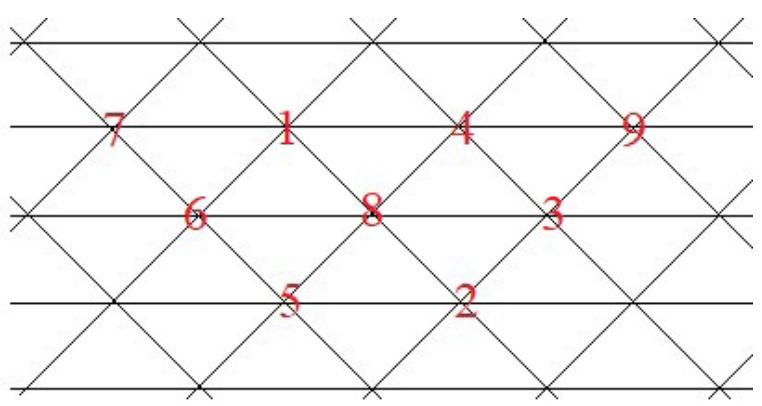

Fig. 5. Arrangement of all repair stations

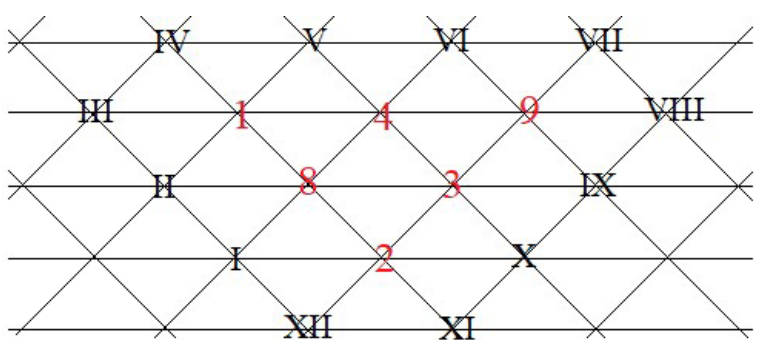

Fig. 4. Indication of possible nodes for the placement of the next object

ground vehicles or a naturally limited allocation area. However, the presented negative effects of using the method are not so significant, because they can be compensated by rather uncomplicated calculations and the possibility to correct the obtained result. The proposal to optimize the organization of the repair process using the BlochSchmigalla method entails numerous advantages, such as decreasing the volume of the transport activity size or time saving resulting from the rational arrangement of repair stations for unmanned ground vehicles.

Table 6. Determination of the transport activity size and indication of the next station's location

\begin{tabular}{|c|c|c|c|c|c|c|c|c|c|c|}
\hline \multicolumn{10}{|c|}{ Transport activity size } \\
\hline & I & II & III & IV & V & VI & VII & VIII & IX \\
\hline 1 & 13 & 13 & 26 & 26 & 26 & 26 & 26 & 13 & 13 \\
\hline 4 & 140 & 70 & 70 & 70 & 70 & 140 & 140 & 140 & 140 \\
\hline 8 & 72 & 72 & 72 & 72 & 36 & 36 & 36 & 36 & 72 \\
\hline$\Sigma$ & 225 & 155 & 168 & 168 & 132 & 202 & 202 & 189 & 225 \\
\hline
\end{tabular}

Table 7. Determination of the transport activity size and indication of the next repair station

\begin{tabular}{|c|c|c|c|c|c|c|c|c|c|c|}
\hline \multicolumn{10}{|c|}{ Transport activity size } \\
\hline & I & II & III & IV & V & VI & VII & VIII & IX & X \\
\hline 1 & 11 & 11 & 22 & 22 & 33 & 33 & 22 & 22 & 11 & 11 \\
\hline 4 & 140 & 70 & 70 & 70 & 140 & 140 & 140 & 140 & 140 & 140 \\
\hline 8 & 36 & 36 & 36 & 36 & 36 & 36 & 18 & 18 & 18 & 36 \\
\hline 3 & 180 & 120 & 120 & 60 & 60 & 60 & 60 & 120 & 120 & 180 \\
\hline$\Sigma$ & 367 & 237 & 248 & 188 & 269 & 269 & 240 & 300 & 289 & 367 \\
\hline
\end{tabular}

Table 8. Determination of the transport activity size and indication of the next work station

\begin{tabular}{|c|c|c|c|c|c|c|c|c|c|c|c|c|}
\hline \multicolumn{10}{|c|}{ Transport activity size } \\
\hline & $\mathrm{I}$ & $\mathrm{II}$ & $\mathrm{III}$ & $\mathrm{IV}$ & $\mathrm{V}$ & $\mathrm{VI}$ & $\mathrm{VII}$ & $\mathrm{VIII}$ & $\mathrm{IX}$ & $\mathrm{X}$ & $\mathrm{XI}$ \\
\hline 1 & 19 & 19 & 38 & 57 & 57 & 57 & 57 & 38 & 38 & 19 & 19 \\
\hline 4 & 32 & 16 & 16 & 32 & 32 & 32 & 32 & 32 & 32 & 32 & 32 \\
\hline 8 & 104 & 104 & 104 & 156 & 156 & 104 & 104 & 52 & 52 & 52 & 104 \\
\hline 3 & 30 & 20 & 20 & 20 & 20 & 10 & 10 & 10 & 20 & 20 & 30 \\
\hline 9 & 81 & 54 & 27 & 27 & 27 & 27 & 54 & 54 & 81 & 81 & 81 \\
\hline$\Sigma$ & 266 & 213 & 205 & 292 & 292 & 230 & 257 & 186 & 223 & 204 & 266 \\
\hline
\end{tabular}


Table 9. Determination of the transport activity size and indication of the next work station

\begin{tabular}{|c|c|c|c|c|c|c|c|c|c|c|c|c|c|}
\hline \multicolumn{10}{|c|}{ Transport activity size } \\
\hline & I & II & III & IV & V & VI & VII & VIII & IX & X & XI & XII & XIII \\
\hline 1 & 24 & 24 & 24 & 48 & 72 & 72 & 72 & 72 & 72 & 72 & 72 & 48 & 48 \\
\hline 4 & 16 & 16 & 8 & 8 & 8 & 16 & 16 & 16 & 24 & 24 & 24 & 24 & 24 \\
\hline 8 & 16 & 16 & 16 & 16 & 24 & 24 & 16 & 16 & 16 & 16 & 16 & 16 & 16 \\
\hline 3 & 33 & 33 & 22 & 22 & 22 & 22 & 11 & 11 & 22 & 22 & 33 & 33 & 33 \\
\hline 9 & 30 & 30 & 20 & 10 & 10 & 10 & 10 & 20 & 30 & 30 & 40 & 40 & 40 \\
\hline 2 & 54 & 54 & 54 & 54 & 54 & 54 & 36 & 18 & 18 & 18 & 36 & 36 & 54 \\
\hline 5 & 18 & 27 & 27 & 27 & 36 & 36 & 27 & 18 & 18 & 9 & 9 & 9 & 18 \\
\hline 6 & 32 & 64 & 64 & 96 & 128 & 128 & 96 & 96 & 96 & 64 & 64 & 32 & 32 \\
\hline$\Sigma$ & 223 & 264 & 235 & 281 & 354 & 362 & 284 & 267 & 296 & 255 & 294 & 238 & 265 \\
\hline
\end{tabular}

\section{Acknowledgements}

The article was written as part of the implementation of the university research grant supported by Military University of Technology (No 747/WAT/2020).

\section{REFERENCES}

1. Babac S., Belić, D. Permaculture Zone Planning Using the Triangular Method. Electronic Journal of the Faculty of Civil Engineering Osijek-e-GFOS, 17, 2018, 100-110.

2. Banduka N., Mladineo M., Eric M. Designing a layout using Schmigalla method combined with software tool vistable. International Journal of Simulation Modelling 16(3), 2017, 375-385.

3. Belic D., Kunica Z., Opetuk T., Goran D. Optimization of the Plant Layout in the Production of the Special Transformers - Case Study, FME Transactions 46, 2018, 285-290.

4. D-4(B) Doktryna logistyczna Sił Zbrojnych Rzeczypospolitej Polskiej, Szt. Gen. 888/2014, Bydgoszcz 2014.

5. Dąbrowski M. Roboty lądowe na polu walki, Przegląd Sił Zbrojnych nr 1/2019. Wojskowy Instytut Wydawniczy, 2019.

6. DD 4.22 Zabezpieczenie techniczne SZ RP. Zasady funkcjonowania, Bydgoszcz 2012.

7. DD 4.22.10 Zasady i organizacja obsługiwań i naprawy sprzętu w warunkach polowych, Bydgoszcz 2013.

8. Depczyński M. Robotyzacja pola walki, Przegląd Sił Zbrojnych nr 5/2017, Wojskowy Instytut Wydawniczy, 2017.

9. Ficko M., Palcic I. Designing a layout using the modified triangle method, and genetic algorithms. International Journal of Simulation Modelling 12(4), 2013, 237-251.

10.http://mfiles.pl/pl/index.php/Metoda_Blocha-
Schmigalli (available at 24.07.2019).

11. Israeli robot expert: West 10 years ahead of "enemy" in warfare technology, http://www.jpost.com/ Business-and-Innovation/Israeli-robotics-expertWest-10-years-ahead-of-enemy-in-warfare-technology-435494 (available at 30.06.2017).

12. Korgul P., Konopka S., Łopatka M.J. Accuracy Control Studies of Engineer Robot Manipulator of Serial-to-Parralel Kinematic Structure. Proceeding of 23rd International Conference on Methods and Models in Automation and Robotics, MMAR 2018 October 2018, 498-502.

13. Krolczyk J. B., Krolczyk G. M., Legutko S., Napiorkowski J., Hloch S., Foltys J., Tama E. Material flow optimization - a case study in automotive industry. Tehnicki vjesnik 22(6), 2015, 1447-1456.

14. Lis S., Santarek K. Projektowanie rozmieszczenia stanowisk roboczych, Wydawnictwo Naukowe PWN, 1980.

15. Łopatka M. J. Heavy robots for C-IED operations. 1st International Scientific Conference and Live Firing Show on Challenges to National Defence in the Contemporary Geopolitical Situation (CNDCGS). Lithuania 2018, 60-66.

16. Łopatka M. J., Muszyński T., Polis W. Modułowe lekkie bezzałogowe platformy lądowe wsparcia. Szybkobieżne pojazdy gąsiennicowe, 3(45), 2017, 33-48.

17. Malon, K., Łopatka, J., Rykała, Ł., Łopatka, M. Accuracy analysis of UWB based tracking system for unmanned ground vehicles. Proceedings of the International Conference on New Trends in Signal Processing, NTSP 2018, Demanovska Dolina, Slovakia 2018, 99-105.

18. Massey K. Squad Mission Equipment Transport (SMET). Lessons Learned for Industry, NDIA Ground Robotics Capability Conference 2016.

19. Mierczyk Z. (red.) Nowoczesne technologie systemów uzbrojenia. Wojskowa Akademia Techniczna, 2008.

20. Mikołajczyk Z. Techniki organizatorskie 
W rozwiązywaniu problemów zarządzania. Wydawnictwo Naukowe PWN, 2002.

21. Potocki A. Zastosowanie metody H. Schmigalli do optymalizacji rozmieszczenia stanowisk biurowych. Zeszyty Naukowe AE, Kraków 105/1987.

22. Russian military is reading for robot wars, International military review, https://southfront.org/russian-military-is-readying-for-robot-wars/ (available at 30.06.2017).

23. Syrian army use military robots made in Russia, http://www.fort-russ.com/2015/12/syrian-armyuse-military-robots-made-in.html (available at 30.06.2017).
24. Łopatka, M.J., Muszynski, T. Analysis of Dismounted Operation Support with Robots. Conference Proceedings Challenges to National Defence in the Contemporary Geopolitical Situation - CNDCGS’2018, Lithuania 2018, 25-27.

25. Łopatka, M.J., Muszynski, T. Future Robots Using in C-IED Detection. Conference Proceedings Challenges to National Defence in the Contemporary Geopolitical Situation - CNDCGS' 2018, Lithuania 2018, 25-27.

26. Łopatka, M.J., Sterniczuk, D. Concept of the Manipulators Set for Fast IEDs Neutralization. (2018) AIP Conference Proceedings, 2029, art. no. 020037. 